\title{
Design \& Weight Optimization of a Wheel Rim for Sport Utility Vehicle.
}

\author{
Harish Panjagala ${ }^{1, *}$, Balakrishna $M^{2}$, Shasikant Kushnoore ${ }^{1}$ and E L N Rohit Madhukar ${ }^{3}$ \\ ${ }^{1}$ Faculty of Mechanical Engineering, Koneru Lakshmaiah Educational Foundation, Vaddeswaram, Guntur, Andhra Pradesh, India - \\ 522502 . \\ ${ }^{2}$ Faculty of Mechanical Engineering, G.I.E.T, Rajahmundry, Andhra Pradesh, India. \\ ${ }^{3}$ Department of Mechanical Engineering, Koneru Lakshmaiah Educational Foundation, Vaddeswaram, Guntur, Andhra Pradesh, India \\ $-522502$.
}

\begin{abstract}
Automobile have various parts which are important for good running of the vehicle. The most important safety components from a structural point of view are the road wheels. They are required to be lighter and more fascinating to the buyer all the time. This implies that it's important to perform a lot of accurate strength assessment on wheel styles. The wheel rim plays a major role in vehicle dynamics. This paper deals with the design and model of different wheel rims based on weight optimization and also structural analysis has been carried out. It has been compared with standard values by varying two different materials. In addition, from the obtained outputs of simulations and the weight optimization, we suggested Aluminium alloys as most suitable material for SUV. Model is created by using SOLIDWORKS software 2015 and structural analysis \& weight optimization is done by using ANSYS WORKBENCH 16.0.
\end{abstract}

\section{INTRODUCTION}

A sport or suburban utility vehicle (SUV) is similar to a local wagon or estate car, and are usually use with fourwheeled drive for on- and-off road ability, as well as provide additional cargo capacity in the form of a two box design with shared passenger volume with rear cargo access via a lift gate, rather than a separate lower height trunk cargo space with a horizontal lid. The wheel rim is important structural member of vehicle suspension system which supports static as well as dynamic load encountered during vehicle operation. They must design it carefully. Safety and economy are major concern while designing. Also Style, weight, manufacturability and performance are the technical issues related to the design of wheel rim.

Automotive manufacturers are working on developing fuel effective, safe and lightweight vehicle components. In the actual service conditions, finding of mechanical behavior for the wheel is important, but the testing and inspection of the wheels during their development process is time consuming and costly. For economic reasons, it is important to reduce the time spent during the development and testing phase of a new wheel rim. For this purpose, Finite Element Analysis (FEA) is generally used in the design stage of product development to investigate the mechanical performance of prototype designs. FEA simulation of the wheel rim can significantly reduce the time and cost required to finalize the wheel design.

T. Siva Prasad et al [1] worked with the wheel rim designed by using modeling software CATIAv5r18. Later this CATIA model is imported to ANSY'S for analysis work. ANSYS static analysis work is carried out by considered two different materials namely Aluminum and forged steel and their relative performances have been observed respectively. Sourav Das et al [2] carried the design of Aluminum alloy wheel for automobile application which is carried out paying special reference to optimization of the mass of the wheel.

S. Ganesh et al [3] described parametric model is designed for Alloy wheel used in four wheelers by collecting data from reverse engineering process from existing model. P. Meghashyam et al [4] described static analysis work by considering two different materials namely Aluminum and forged steel and their relative performances have been observe respectively by using ANSY'S Software.

P. Ramamurthy Raju et al [5] concerning with generation of S-N curve for Aluminum alloy (Al) A356.2-T6 and estimation of fatigue life under radial fatigue load. The S-N curve is generated by conducting different tests at different stress levels under constant amplitude loading.

From the above mentioned references, we observed that there is a need to reduce weight of wheel rim and also it should contain high strength. For that reason, we used Topology optimization tool in Ansy's Workbench to find the unnecessary region based on that by changing the design, we optimized the mass of wheel rim by using strength calculations and analyzing the rim using Ansy's Simulation software, finally from the results of structural analysis and the weight optimization, we suggest a suitable material of wheel rim for SUV.

\footnotetext{
Harish Panjagala: panjagalaharish@kluniversity.in
} 


\section{Theoretical Analysis}

\subsubsection{Moment on wheel rim :}

Net mass of SUV (M) $=2134 \mathrm{~kg}$ (hummer H3)

Mass of SUV without wheel rim $=$ net mass - (mass of wheel $\operatorname{rim}^{*} 4$ )

Let mass of wheel rim is $16.5 \mathrm{~kg}$.

Mass of SUV without wheel $\operatorname{rim}(\mathrm{m})=2134-66=$ $2068 \mathrm{~kg}$.

The weight acting on a front wheel $\operatorname{rim}(\mathrm{F})=\mathrm{m} *$ aspect ratio $*$ gravity $/ 2 .=2068 * 6 * 9.8 / 2=6080 \mathrm{~N}$

Moment on wheel $\mathrm{rim}=\mathrm{F}^{*} \mathrm{R}=6080 * 0.217=1320 \mathrm{Nm}$

\subsubsection{Bending moment:}

The bending moment to be imparted in the test shall be in accordance to the following formula:

$\mathrm{M}=((\mathrm{f} * \mathrm{R})+\mathrm{d}) * \mathrm{~F} * \mathrm{~S}$

Where,

$\mathrm{f}=$ frictional coefficient between the tire and road surface $\mathrm{R}=$ radius of the tire

$\mathrm{d}=$ offset of the wheel (equal to 0 for zero offset position)

$\mathrm{F}=$ Maximum load acting on the wheel rim

$\mathrm{S}=$ coefficient specified according to the standards

Tire specification radial $=216 / 60 \mathrm{R} 17$

Where, 216 is the section width in $\mathrm{mm} 60$ is the aspect ratio in percentage 17 is the diameter of the wheel rim in inches $\mathrm{f}=0.7 \mathrm{R}=0.217 \mathrm{~m}$

$\mathrm{S}=$ section width*aspect ratio $=216 * .6=0.130$

Now bending moment $=\left(.7^{*} .217\right) * 6080 * .13$ $=724.79 \mathrm{Nm}$

\subsubsection{Radial endurance test:}

The radial load to be imparted in the test shall be in accordance with the following formula;

$\mathrm{Fr}=\mathrm{F}^{*} \mathrm{k}$

$\mathrm{F}=$ the maximum load of coming on the tire in $\mathrm{N}$

$\mathrm{k}=$ constant value according to the industrial standards= 0.453

$\mathrm{Fr}=6080 * .453=2754.24 \mathrm{~N}$

\subsection{Specifications:}

$\begin{array}{ll}\text { Rim diameter } & =434 \mathrm{~mm} \\ \text { Width of rim } & =216 \mathrm{~mm} \\ \text { Wheel type } & =\text { alloy wheel rim } \\ \text { Aspect ratio } & =6: 4 \\ \text { No. of bolts } & =6 \\ \text { Pitch diameter of bolt } & =120 \mathrm{~mm} \\ \text { Size of bolt } & =16 \mathrm{~mm}(16 \mathrm{M})\end{array}$

\subsection{Properties of Materials:}

\section{A. Aluminum alloys}

Density $=2770 \mathrm{~kg} / \mathrm{m}^{3}$

Coefficient of Thermal Expansion $=2.3 * 10^{-005} /{ }^{0} \mathrm{C}$

Specific Heat $=875 \mathrm{~J} / \mathrm{kg}{ }^{0} \mathrm{C}$

\section{B. Structural steel}

Density $=7850 \mathrm{~kg} / \mathrm{m}^{3}$

Coefficient of Thermal Expansion $=1.2 * 10^{-005} /{ }^{0} \mathrm{C}$

Specific Heat $=434 \mathrm{~J} / \mathrm{kg}{ }^{0} \mathrm{C}$

\subsection{Design Procedure of Wheel Rim in Solid works:}

1. Created a $2 \mathrm{D}$ sketch on front plane as shown in the figure.

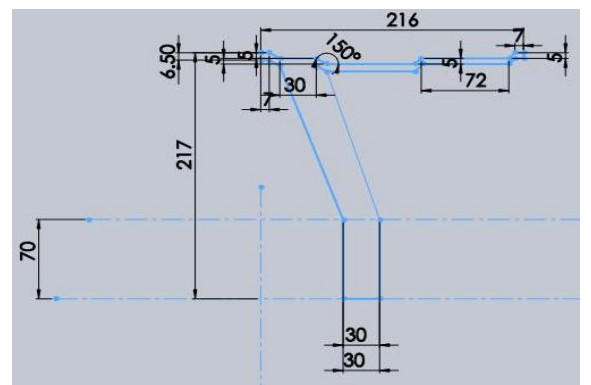

Fig 1. Design of wheel rim (2D) in Solid Works Software

2. Revolved, the sketch to 360 degrees on bottom line, by (Insert>Boss/base $>$ Revolve) ok.

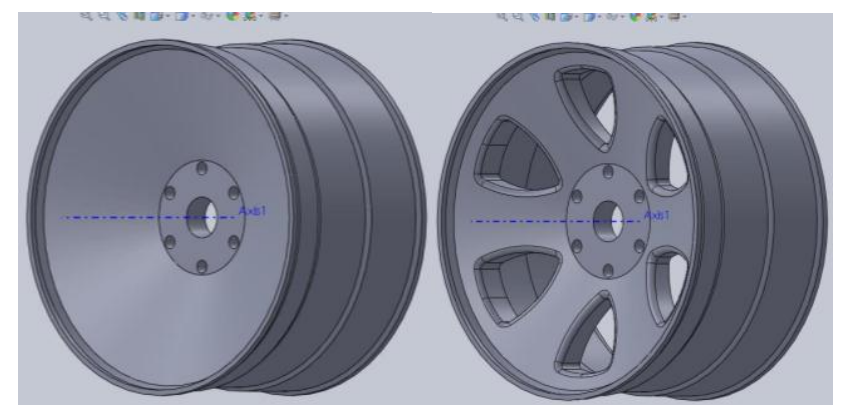

Fig 2. 3D design of wheel rim [Basic Model] \& Model 1, (first Weight Optimization model of wheel rim) in Solid Works.

3. Draw the sketch on edge wheel rim face, sketch for arm hole. And remove the material by (insert $>$ cut $>$ extrude cut), through all, ok.

4. Add fillet on the cutting edge, click circular pattern by (view $>$ temporary axis) select center axis as rotation axis.

5. (Give 360 degree and 6 equal spacing), Select cutExtrude, fillet 1 and fillet 2 as a Feature to pattern. Ok.

6. Repeat the procedure no. 3,4 and 5 for the different model design of the wheel rim. as shown in figure 3 .

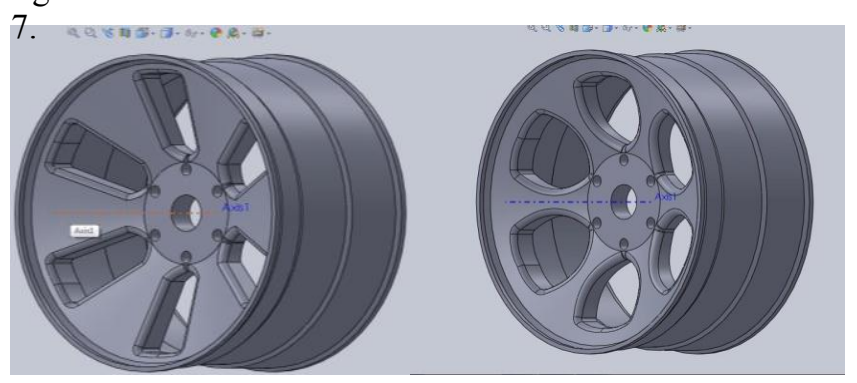

Fig 3. Model 2 \& Model 3 of Wheel rim in Solid Works Software

7. After completing the designing of wheel rim, converted the file from. SLDPRT to. STEP file for analysis the wheel rim on ANSYS software 16.0. 


\section{Results \& Discussions}

\subsection{Aluminium Alloys Wheel Rim:}

3.1.1 Basic Model:

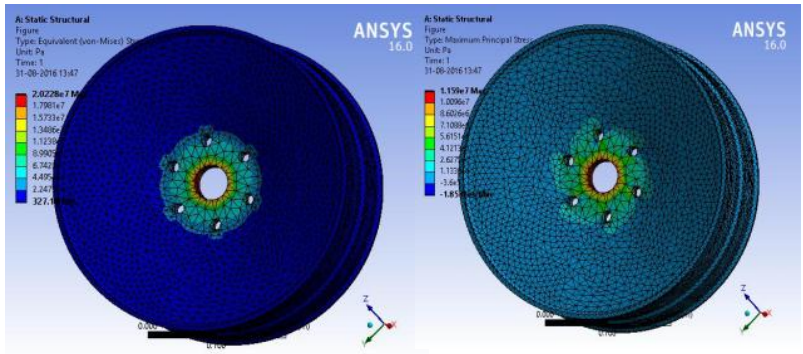

Fig 4. Equivalent stress \& Maximum Principal stress on Basic Model of wheel rim.

Here, the maximum equivalent stress generated on the Basic Model is $20.22 \mathrm{MPa}$, which is maximum at the center of the wheel rim as shown in figure 4. And the Maximum Principal stress generated on the Basic model of Aluminum alloys wheel rim is $11.59 \mathrm{MPa}$ as shown in above figure 4 . Now, the total weight or mass of the Basic model of Aluminum alloys wheel rim is 16.640 $\mathrm{kg}$, which is calculated by using Ansy's Workbench 16.0 Software.

\subsubsection{Model 1}

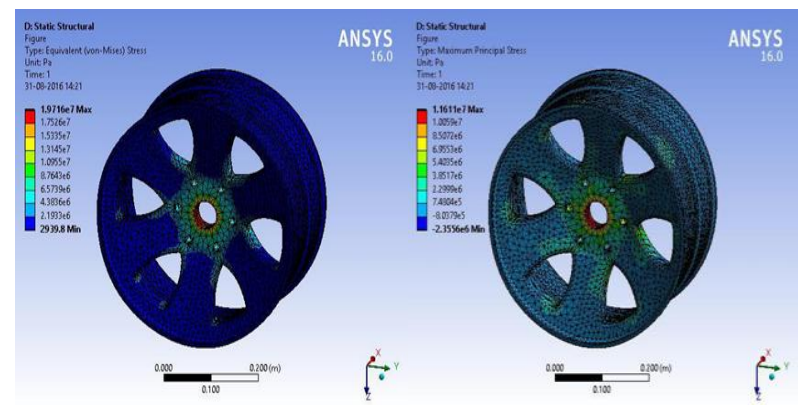

Fig 5. Equivalent stress \& Maximum Principal Stress generated on the Model 1-wheel rim

The equivalent stress generated on the Model 1 Wheel rim is $19.71 \mathrm{MPa}$ as shown in figure 5 . The maximum equivalent stress generated at the center of the wheel rim, which is represented by red color as shown in above figure 5. The Maximum Principal stress generated on the Model 1 of Aluminium alloys wheel rim is 11.6MPa. The actual weight or mass of the Model 1 of Aluminium alloys wheel is $13.484 \mathrm{~kg}$, which is less than the Basic model of wheel rim. The total percentage of reduction is $18.96 \%$.

\subsubsection{Model 2}

Here, the maximum equivalent stress generated on the Model 2 Aluminium alloys Wheel rim is $20.05 \mathrm{MPa}$, and the maximum equivalent stress is generated or developed on the center of the wheel rim as shown in figure 6. Now, the maximum Principal stress developed on the Model 2 of Aluminium alloys wheel rim is $12.989 \mathrm{MPa}$, and which is maximum at the center of the wheel rim figure 6. The mass of the Model 2 of Aluminium alloys Wheel rim is $12.107 \mathrm{~kg}$ which is generated or solved by using the Ansy's Workbench 16.0. The total percentage of weight reduction for the Model 2 Wheel rim is $27.24 \%$.

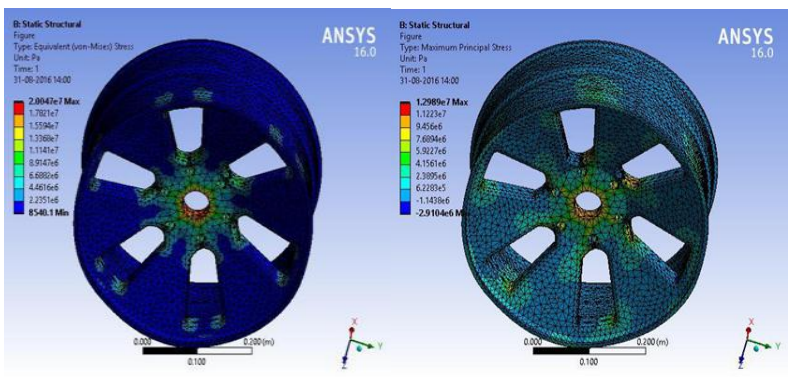

Fig 6. Equivalent stress \& Maximum Principal Stress generated on the Model 2-wheel rim

\subsubsection{Model 3}

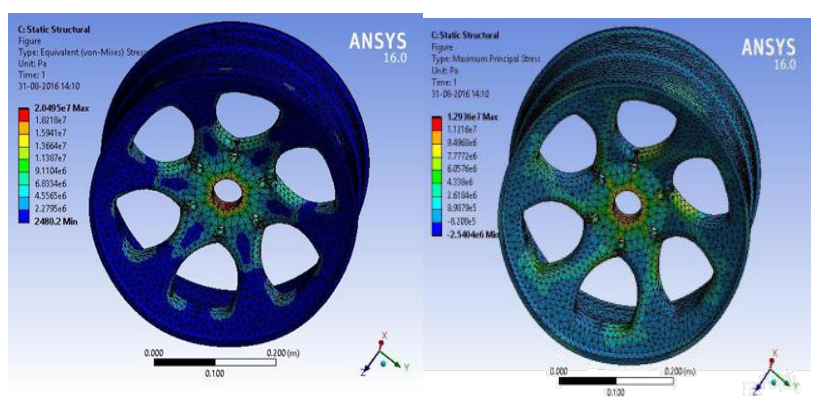

Fig 7. Equivalent stress \& Maximum Principal Stress for Model 3-wheel rim

Here, the maximum equivalent stress generated on the Model 3 Aluminium alloys Wheel rim is $20.5 \mathrm{MPa}$, and the maximum equivalent stress is generated on the center of the wheel rim as shown in above figure 7 . Then, the maximum Principal stress generated on the model 3-wheel rim is $12.936 \mathrm{MPa}$ as shown in figure 7 . And the mass or weight of the Model 3 Aluminium alloys Wheel rim is $11.032 \mathrm{~kg}$. Total percentage of weight reduction is $33.70 \%$. And this is the final model of wheel rim, which are designed.

\subsection{Structural Steel Wheel Rim:}

\subsubsection{Basic Model}

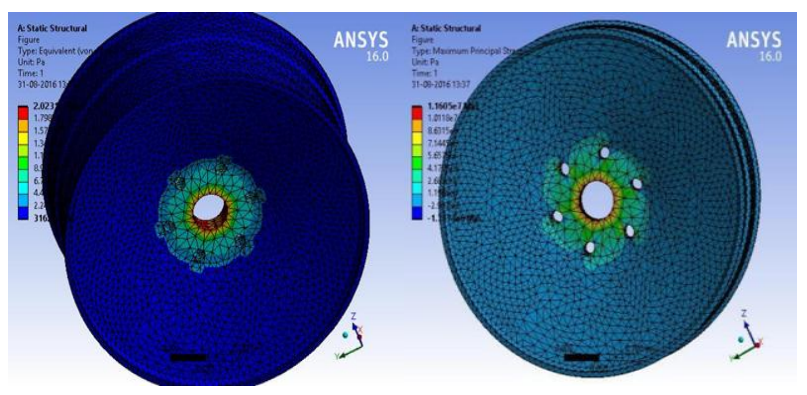

Fig 8. Equivalent Stress \& Maximum Principal Stress for Basic model of wheel rim

Here, the maximum equivalent stress generated on the Basic Model is $20.23 \mathrm{MPa}$, which is maximum at the 
center of the wheel rim as shown in below figure 8. And the Maximum Principal stress generated on the Basic model of Structural steel wheel rim is $11.60 \mathrm{MPa}$ as shown in below figure 8 . Now, the total weight or mass of the Basic model of Structural steel wheel rim is $47.158 \mathrm{~kg}$, which is calculated by using Ansy's Workbench 16.0 Software.

\subsubsection{Model 1}

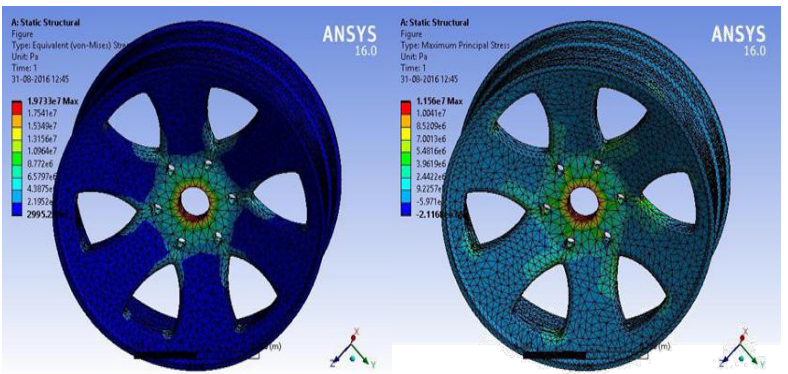

Fig 9. Equivalent Stress \& Maximum Principal Stress generated on the Model 1-wheel rim

The equivalent stress generated on the Model 1 of Structural steel Wheel rim is $19.73 \mathrm{MPa}$ as shown in above figure. The maximum equivalent stress generated at the center of the wheel rim, which is represented by red color as shown in above figure 9. The Maximum Principal stress generated on the Model 1 of Structural steel wheel rim is $11.56 \mathrm{MPa}$. The actual weight or mass of the Model 1 Structural steel wheel is $38.212 \mathrm{~kg}$, which is less than the Basic model of wheel rim. The total percentage of weight reduction is $18.97 \%$.

\subsubsection{Model 2}

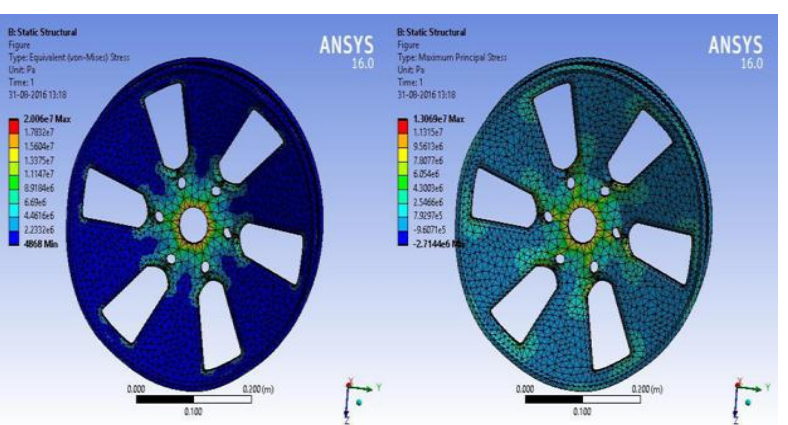

Fig 10. Equivalent Stress diagram for model $2 \&$ Maximum Principal Stress diagram for model 2 of wheel rim

Here, the maximum equivalent stress generated on the Model 2 of Structural steel Wheel rim is $20.06 \mathrm{MPa}$, and the maximum equivalent stress is generated or developed on the center of the wheel rim as shown in above figure 10 . Now, the maximum Principal stress developed on the Model 2 of Structural steel wheel rim is $13.069 \mathrm{MPa}$, and which is maximum at the center of the wheel rim as shown in above figure 10. The mass of the Model 2 of Structural steel Wheel rim is $37.144 \mathrm{~kg}$ which is generated or solved by using the Ansy's Workbench 16.0. The total percentage of weight reduction for the Model 2 Wheel rim is $21.23 \%$.

\subsubsection{Model 3}

Here, the maximum equivalent stress generated on the Model 3 of Structural steel Wheel rim is $20.5 \mathrm{MPa}$, and the maximum equivalent stress is generated or developed on the center of the wheel rim as shown in above figure. Now, the maximum Principal stress developed on the Model 3 of Structural steel wheel rim is $12.971 \mathrm{MPa}$, and which is maximum at the center of the wheel rim as shown in above figure. The mass of the Model 3 of Structural steel Wheel rim is $34.098 \mathrm{~kg}$ which is generated or solved by using the Ansy's Workbench 16.0. The total percentage of weight reduction for the Model 3 Wheel rim is $27.69 \%$.

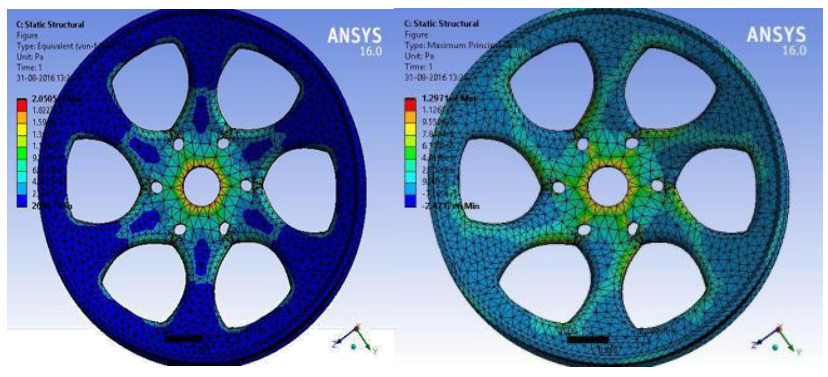

Fig 11. Equivalent Stress \& Maximum Principal Stress for Model 3 of wheel rim

Table 1 Mass and Equivalent stress for Aluminium alloys and Structural steel

\begin{tabular}{|c|c|c|c|}
\hline \multirow[b]{2}{*}{ Model } & \multirow{2}{*}{$\begin{array}{c}\text { Equivalent } \\
\text { Stress (Mpa) }\end{array}$} & \multicolumn{2}{|c|}{ Mass Of Wheel Rim } \\
\hline & & $\begin{array}{l}\text { Aluminium } \\
\text { Alloys (Kg) }\end{array}$ & $\begin{array}{l}\text { Structural } \\
\text { Steel (Kg) }\end{array}$ \\
\hline Basic & 20.22 & 16.640 & 47.158 \\
\hline 1 & 19.71 & 13.484 & 38.212 \\
\hline 2 & 20.05 & 12.107 & 37.144 \\
\hline 3 & 20.50 & 11.032 & 34.098 \\
\hline
\end{tabular}

\subsection{For Aluminium alloys:}

The figure 12 shows the relation between the mass of the wheel rim and equivalent stress developed in the wheel rim. Here the first point on the graph represented the mass for the model 1 of the wheel rim, where the mass of wheel rim is maximum and equivalent stress is less as compared to the model 2 and model 3 . The second point represented the mass of the model 2-wheel rim, whose mass is less than the mass of model 1 as shown in above graph. The Last point is represented the mass for the model 3-wheel rim, whose mass is very less than the other model. Hence, the mass of the final model for Aluminium alloys wheel rim is $11.032 \mathrm{~kg}$ and equivalent stress is $20.50 \mathrm{MPa}$ as shown in the below graph. 


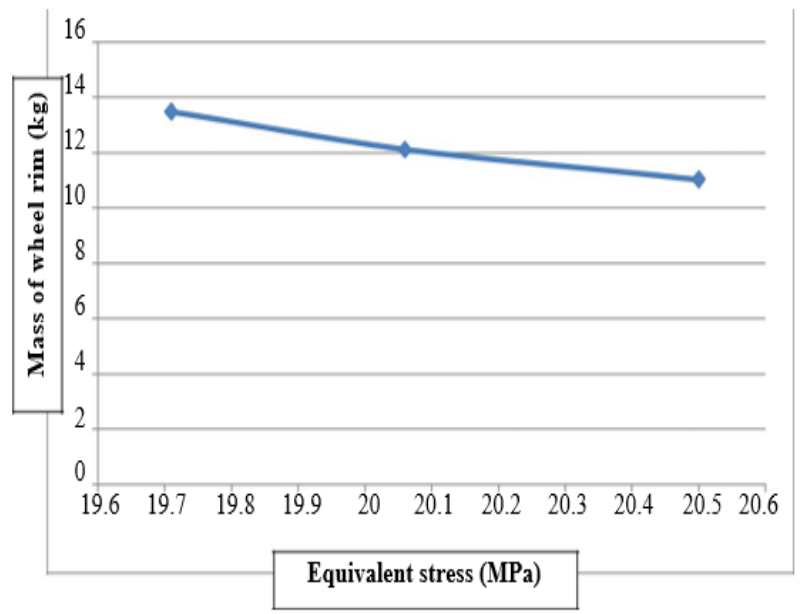

Fig 12. Mass or weight vs. Equivalent stress for the Aluminium wheel rim

\subsection{For Structural steel}

The figure 13 shows the relation between the mass of the wheel rim and equivalent stress developed on the wheel rim. Here the first point on the graph represented the mass for the model 1 of the wheel rim, where the mass of wheel rim is maximum and equivalent stress is less as compared to the model 2 and model 3 . The second point represented the mass of the model 2-wheel rim, whose mass is less than the mass of model 1 as shown in below graph. The Last point is represented the mass for the model 3-wheel rim, whose mass is very less than the other model. Hence, the mass of the final model for Structural steel wheel rim is $34.098 \mathrm{~kg}$ and equivalent stress is $20.50 \mathrm{MPa}$ as shown in the below graph. And when mass of wheel rim decreases, the equivalent stress of wheel rim increases.

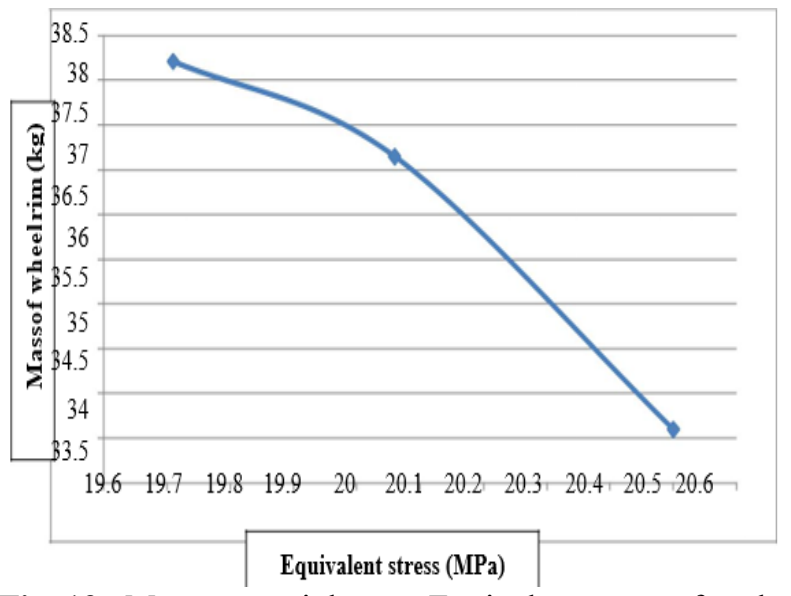

Fig 13. Mass or weight vs. Equivalent stress for the structural steel wheel rim

\section{Conclusion}

Following are the conclusion made from the results obtained from different simulation of the wheel rims made of Structural steel \& Aluminium alloys is;

1. In both cases von-misses / equivalent stresses are less than ultimate strength.

2. In our mini project work, we optimized the wheel rim design to achieve weight reduction. The goal of weight optimization is achieved by comparing the two materials likes structural steel and Aluminium alloys for the SUV vehicle under the same boundary condition.

3. The weight of the wheel rim Aluminium alloys is reduced from $16.64 \mathrm{~kg}$ to $11.032 \mathrm{~kg}$. The strength of the final part or model is $20.5 \mathrm{MPa}$, which is less than ultimate stress $25 \mathrm{MPa}$ as per factor of safety 10 is considered.

\section{References}

[1] T. Siva Prasad, T. Krishnaiah, J. Md. Iliyas, M. Jayapal Reddy, IJISME, Volume no. 2, May 2014, pp.18.

[2] Sourav Das, IJSRP, Volume no.4, 6/ June 2014, pp.1-12.

[3] S. Ganesh, and Dr. P. Periyasamy, IJES, volume no. 3,2014 , pp.29-37.

[4] P. Meghashyam1, S. Girivardhan Naidu and N. Sayed Baba, IJAIEM, Volume no.2, August 2013, 2, pp.1-10.

[5] P. Ramamurthy Raju, B. Satya Narayana, K. Ramji, K. Suresh Babu, November 2006, pp.1-24.

[6] Ravi Lidoriya, Sanjay Chaudhary and Anil Kumar Mohopatra, International Journal of Mechanical Engineering and Research. Volume3, 2013, pp. 503-516.

[7] P. Meghashyam, S. Girivardhan Naidu, and N. Sayed Baba, IJAIEM, volume no. 2, 8/ August 2013, pp. 14-20.

[8] T.V. Rao, K. Deepthi, and K.N.D. Malleswara Rao, IJCER, volume no. 4, October 2014, pp.36-40.

[9] Mayur Khule, and P. Baskar, IJRASET, volume no. 1, May 2016, pp.67-73.

[10] Sushant K. Bawne, Prof. Y.L. Yenarkar, IJERA, volume no.5, October 2015, pp.1-7. 